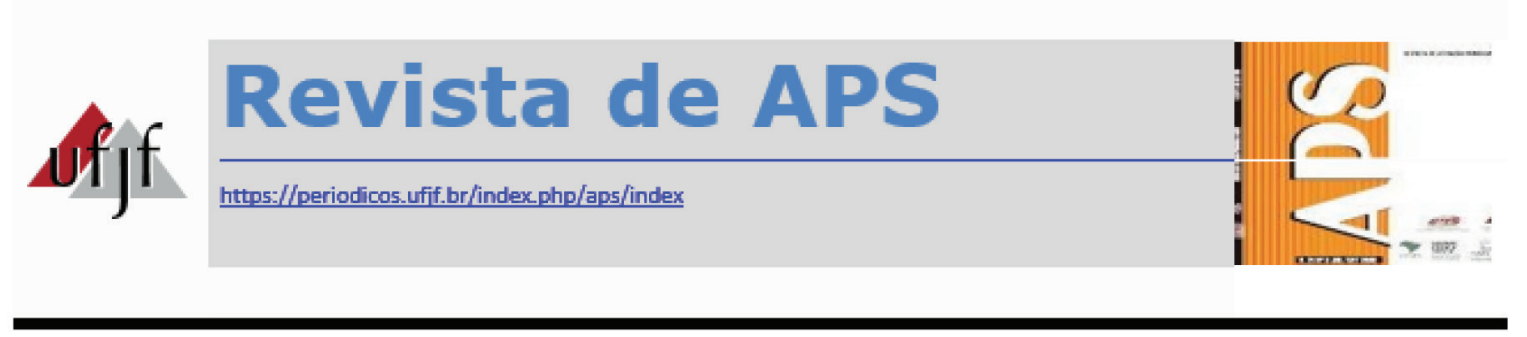

\title{
A saúde do homem e atenção primária à saúde: revisão integrativa
}

\author{
Men's health and primary health care: integrative review
}

Luís Paulo Souza e Souza ${ }^{1}$, Pollyana Mota Oliveira ${ }^{2}$, Sélen Jaqueline Souza Ruas ${ }^{3}$, Adélia Dayane Guimarães Fonseca ${ }^{4}$, Carla Silvana de Oliveira e Silva ${ }^{5}$

\section{RESUMO}

Objetivo: caracterizar a produção científica acerca da saúde do homem no âmbito da atenção primária à saúde, levantando as evidências disponíveis na literatura sobre os motivos que levam à não adesão masculina aos serviços de saúde. Método: trata-se de uma revisão integrativa de literatura. A busca bibliográfica ocorreu na Biblioteca Virtual em Saúde, na base de dados Scientific Eletronic Library Online (SciELO) e Literatura Latino-Americana e do Caribe em Ciências da Saúde (LILACS), levando-se em consideração os artigos publicados entre os anos de 2001 e 2013; publicados em português e disponíveis na integra. Dos 21 artigos encontrados, selecionaram-se 18 para a realização do estudo. Resultados: após análise dos estudos selecionados, chegou-se a três temas que sintetizaram a produção estudada: imaginário masculino; principais barreiras encontradas na busca pelo serviço; e a atuação do profissional na atenção à saúde do homem. Conclusão: foi possível inferir que a produção científica acerca do tema abordado ainda é muito restrita, reforçando a necessidade de aprofundamento no assunto numa perspectiva relacional de gênero e saúde, uma vez que a baixa adesão dos homens aos serviços de atenção básica está fortemente ligada a questões referentes ao imaginário masculino e à

\footnotetext{
${ }^{1}$ Enfermeiro. Doutorando em Saúde Pública pela Faculdade de Medicina da Universidade Federal de Minas Gerais UFMG. Professor do Departamento de Medicina da Universidade Federal de São João Del Rei, Campus Dom Bosco, São João Del Rei - MG, Brasil. E-mail: luis.pauloss@hotmail.com

${ }^{2}$ Enfermeira graduada pela Universidade Estadual de Montes Claros. Enfermeira da Prefeitura Municipal de Januária - MG, Brasil.

${ }^{3}$ Enfermeira. Especialista em Saúde da Família. Professora do Departamento de Enfermagem das Faculdades de Saúde Ibituruna, Montes Claros - MG, Brasil.

${ }^{4}$ Enfermeira. Doutora em Ciências da Saúde pela Universidade Estadual de Montes Claros. Professora do Departamento de Enfermagem da Universidade Federal de Juiz de Fora, MG, Brasil.

${ }^{5}$ Enfermeira. Doutora em Ciências pela Universidade Federal de São Paulo. Professora do Departamento de Enfermagem da Universidade Estadual de Montes Claros, Montes Claros - MG, Brasil.
} 
manutenção do ideal de invulnerabilidade, que constitui importante fator de risco à saúde do homem.

PALAVRAS-CHAVE: Saúde do Homem. Atenção Primária à Saúde. Estratégia Saúde da Família. Educação em Saúde.

\begin{abstract}
Objective: to characterize the scientific production about man's men's health in primary health care, by raising the available evidence in the literature about the main reasons that lead to non-adherence male health services. Method: this is an integrative review of the literature. The bibliographic search occurred in Virtual Health Library, in the database Scientific Electronic Library Online - SciELO and Latin American and Caribbean Center on Health Sciences - LILACS, taking into consideration articles published between the years of 2001 and 2013; published in Portuguese and available in its entirety. Of the 21 articles found, 18 were selected for the study. Results: after the analysis of the selected studies, three themes were reached that synthesized production studied: male imaginary; major barriers encountered in the pursuit of the service; and professional performance in men's health care. Conclusion: it was possible to infer that the scientific literature on the subject is still very restricted, reinforcing the need to deepen the subject in a relational perspective of gender and health, since the low adhesion of men to basic services is strongly linked to issues related to the imaginary masculine and ideal maintenance of invulnerability, which is an important risk factor for human health.
\end{abstract}

KEYWORDS: Men's Health. Primary Health Care. Family Health Strategy. Health Education.

\title{
INTRODUÇÃO
}

A Atenção Primária à Saúde caracteriza-se como um conjunto de ações de saúde no âmbito individual e coletivo, que abrange a promoção e a proteção da saúde, a prevenção de agravos, o diagnóstico, tratamento, reabilitação, redução de danos e manutenção da saúde, tendo como objetivo desenvolver uma atenção integral que impacte melhoria na situação de saúde da população e seus determinantes. ${ }^{1}$

A promoção da saúde, que é a combinação de ações planejadas da população, dos serviços de saúde, das representações sanitárias e de outros setores sociais em apoio à melhoria de hábitos de vida para o desenvolvimento de melhores condições de saúde individual e coletiva, visa provocar mudanças de comportamento capazes de beneficiar camadas mais amplas da sociedade. De forma restrita, por outro lado, a prevenção está baseada na concepção de risco ou de probabilidade de se tornar doente, direcionando seus estudos e intervenções para grupos restritos. ${ }^{2}$

Assim, as práticas preventivas significam impedir o desenvolvimento de uma doença antes que ela ocorra. Desse modo, as ações preventivas são definidas como 
intervenções direcionadas para o surgimento de doenças específicas, reduzindo sua incidência e prevalência na população. ${ }^{2}$

Ressalta-se que as ações de promoção da saúde adquirem importante papel socioeconômico e cultural, principalmente naquelas populações com mais vulnerabilidade, envolvendo seus potenciais de enfrentamento, adoecimento e não adoecimento, além dos altos riscos. Essa população é definida como chances maiores de adoecimento e morte por agravos, muitas vezes preveníveis, como é o caso da população masculina, uma vez que por questões ligadas à ideologia de gênero, os homens acabam por negligenciar sua própria saúde. ${ }^{3-33}$

É importante reconhecer que essa clientela necessita da elaboração de programas específicos nos quais devam se incluir ações de promoção da saúde e prevenção de agravos, tendo em vista que os homens apresentam percentuais de mortalidade mais elevadas quando comparados às mulheres. Entre as principais causas, destacam-se doenças cardiovasculares, neoplasias malignas, doenças isquêmicas do coração, além de causas externas, tais como acidentes de trânsito e homicídios. ${ }^{3}$

Dados fornecidos pelo Instituto Brasileiro de Geografia e Estatística comprovam essa realidade. Os números demonstram gradativo aumento da mortalidade masculina nas idades jovens e adultas. Nos últimos anos, as taxas de mortalidade masculina, na faixa etária dos 20 aos 29 anos de idade, chegam a ser mais de três vezes superiores às femininas. A maior diferença se estabelece na faixa etária em torno dos 20 anos e após os 60 anos, quando os homens adoecem e morrem mais. Esse quadro tem sido alvo de diversas investigações, considerando o impacto das mortes por causas externas, a saber: homicídios, acidentes de trânsito, suicídios, quedas acidentais, afogamentos, entre outras. ${ }^{4}$ Limitadores importantes para enfrentamento dessa mortalidade pelos serviços de saúde devem ser ressaltados, dado que seus determinantes estão referidos às questões sociais amplas e a políticas públicas como segurança, educação e cultura.

Os homens tendem, por diversos motivos, a assumir comportamentos pouco saudáveis, originando fatores de risco para o adoecimento. Devem ser considerados fatores culturais o modelo da masculinidade hegemônica, que associa expressão de necessidades de saúde à manifestação de fraqueza e de feminilização. A manutenção de tal ideal torna a população masculina mais vulnerável a vários tipos de agravos à saúde ${ }^{5}$

Conforme dados do Ministério da Saúde, ${ }^{6}$ morrem mais homens que mulheres ao longo do ciclo de vida, e muitas dessas mortes poderiam ser evitadas se não existisse uma resistência masculina em relação à procura pelos serviços de saúde. Esses dados sugerem, de forma evidente, a associação entre as principais causas de morte e os aspectos de socialização masculina. ${ }^{7}$

É comprovado, ainda, que existe maior número de homens internados em situação grave, e a procura de serviços de emergência por eles é maior. Evidencia-se, assim, que os homens se inserem no serviço de saúde por meio da atenção terciária, 
tendo como implicação o agravo da morbidade pelo adiamento na atenção, gerando, com isso, mais ônus para o sistema de saúde. Vários estudos comparativos têm confirmado o fato de que os homens são mais vulneráveis às doenças, sobretudo às enfermidades graves e crônicas. ${ }^{8}$

Durante muito tempo, a atenção à saúde foi voltada especificamente para mulheres, crianças e idosos, o que obrigava os homens a terem sua demanda atendida por meio de outros programas voltados para outras clientelas, como programas para idosos, hipertensos e diabéticos. Essa falha detectada no serviço, juntamente com os altos índices de morbimortalidade da população masculina, motivou o lançamento de uma política pública de saúde com a proposta de garantir uma linha de cuidados integrais específica para esse segmento da população.

Entretanto, para além das razões citadas pela falta de atenção à saúde do homem, há de se levar em conta o movimento feminista, que aos poucos foi desconstruindo as posições sociais tradicionais do homem e da mulher. Ao mudar a posição social do homem na sociedade, desconstruindo os papéis de divisão impostos, a relação da mulher com o homem mudou, o que fez com que ele, aos poucos, mudasse igualmente sua posição subjetiva, não apenas com ele mesmo, mas socialmente. ${ }^{9}$

Implantada pelo Governo Federal no ano de 2009 com o intuito de reduzir a morbimortalidade dessa camada populacional evidenciada pelos altos índices de mortalidade e pela baixa procura ao atendimento de saúde, a Política Nacional de Atenção Integral à Saúde do Homem (PNAISH) está integrada com a Política Nacional de Atenção Básica, que constitui a porta de entrada do Sistema Único de Saúde. A não adesão a serviços de Atenção Primária faz com que o indivíduo fique privado da proteção necessária à preservação de sua saúde e permaneça a fazer uso de procedimentos dispensáveis, se a procura houver acontecido em momento anterior. A maioria dos agravos poderia ser evitada caso esses indivíduos realizassem ações de prevenção regulares. A resistência masculina à Atenção Primária acresce não só a sobrecarga financeira da sociedade, mas também o sofrimento físico e emocional do paciente e da família na luta pela conservação da saúde e da qualidade de vida. ${ }^{6-10}$

Tendo em vista todos esses aspectos, surge a seguinte questão: quais os principais motivos que levam a população masculina à não adesão aos serviços da atenção primária à saúde?

Assim, a presente investigação objetivou analisar a produção científica acerca da saúde do homem e a Atenção Primária à Saúde, levantando as evidências disponíveis na literatura sobre os principais motivos da não adesão da população masculina aos serviços de atenção primária, o que se justifica pela relevância do assunto e pela perceptível diminuída presença dessa população nos serviços de saúde. Pretende-se, ainda, contribuir para o conhecimento na área, visto o reduzido número de publicações acerca do tema abordado. 


\section{DESENVOLVIMENTO}

Trata-se de uma revisão integrativa de literatura, que tem a finalidade de reunir e sistematizar resultados de pesquisa sobre um determinado tema ou questão de maneira sistemática e ordenada, contribuindo para o aprofundamento do conhecimento do tema investigado. ${ }^{11}$

A elaboração da revisão integrativa é sistematizada em obediência aos seguintes passos: inicialmente, estabelecimento do objetivo específico; em seguida, formulação dos questionamentos a serem respondidos ou hipótese a ser testada; por fim, levantamento para identificar e coletar o máximo de pesquisas relevantes dentro dos critérios de inclusão e exclusão previamente estabelecidos. O revisor, então, avalia minuciosamente os critérios de métodos empregados no desenvolvimento dos estudos selecionados para determinar se são validados metodologicamente. Esse processo resulta na redução de estudos incluídos na revisão. Os dados coletados são interpretados, sistematizados e as conclusões são formuladas baseando-se nos vários estudos incluídos na revisão integrativa. ${ }^{12,13}$

O processo de elaboração da revisão integrativa se iniciou com a definição de um problema e a formulação de uma hipótese que apresentasse relevância para a saúde: o homem e a atenção primária à saúde, tema que desperta o interesse dos gestores em saúde e torna esse processo mais encorajador, além de ser um problema vivenciado na prática clínica. ${ }^{14}$ Assim, a questão norteadora deste estudo foi: quais os principais motivos que levam a população masculina à não adesão aos serviços da atenção primária à saúde?

Os dados bibliográficos levantados tiveram como finalidade analisar a relação do usuário do sexo masculino com a Atenção Primária à Saúde e compreender os motivos que levam à baixa adesão dessa população a ações de prevenção e autocuidado. A busca bibliográfica se deu no período de março a agosto de 2013. A adoção de critérios para a seleção dos artigos correspondeu aos objetivos do estudo para que houvesse rigor e sistematização. Os seguintes critérios foram considerados: artigos que abordassem a temática saúde do homem na Atenção Primária à Saúde; artigos publicados entre os anos de 2001 e 2013; artigos publicados em língua portuguesa; artigos disponíveis na íntegra. Como critério de exclusão, optou-se por não utilizar textos incompletos e artigos que não estivessem disponíveis na íntegra on-line e gratuitamente. Foram excluídos ainda os livros, teses, dissertações, resenhas, cartas e editoriais, por não terem sidos submetidos à revisão por pares, que é tradição nas publicações científicas para que seja mantida a qualidade das publicações.

Para a coleta de dados, foram utilizadas as bases de dados da Scientific Eletronic Library Online (SCIELO) e Literatura Latino-Americana e do Caribe em Ciências da Saúde (LILACS), cujo acesso se deu por meio da Biblioteca Virtual em Saúde (BVS) com 
a utilização dos seguintes descritores: Saúde do Homem, Atenção Primária à Saúde, Identidade de Gênero, Educação em Saúde, Cultura, Programa Saúde da Família.

Como mostra a Tabela 1, foram encontrados 21 artigos e, após a leitura minuciosa, foram selecionados 18 para a realização do presente estudo. A análise foi feita de forma crítica, procurando explicações para os resultados diferentes ou conflitantes nos diversos trabalhos, sendo predominantemente de cunho qualitativo, ou seja, em vez de se chegar aos temas pela utilização de medidas, procurou-se interpretar os sentidos das ideias centrais dos artigos (Tabela 1).

Tabela 1 - Relação dos artigos encontrados e selecionados segundo descritores. Montes Claros, 2013

\begin{tabular}{ccc}
\hline $\begin{array}{c}\text { Descritores usando operador booleano } \\
\text { "and" }\end{array}$ & Artigos encontrados & Artigos selecionados \\
\hline Saúde do homem and atenção primária à & 09 & 08 \\
saúde & 06 & 05 \\
Saúde do homem and identidade de gênero & 03 & 02 \\
Saúde do homem and educação em saúde & 02 & 02 \\
Saúde do homem and Programa Saúde da & 01 & 01 \\
Família & 21 & 18 \\
Saúde do homem and Cultura & Total & 02 \\
\hline
\end{tabular}

Fonte: elaborado pelos autores

Para a análise, os estudos foram organizados com os seguintes itens: título do artigo; periódico e ano de publicação; método utilizado; autores; breve resumo do trabalho, conforme se observa no Quadro 1.

Quadro 1 - Apresentação da síntese dos artigos incluídos nesta revisão. Montes Claros, 2013

\begin{tabular}{|l|c|c|c|c|l|}
\hline Título do Artigo & Autores & Periódico & Ano & Método & Resumo \\
\hline $\begin{array}{l}\text { Questões de } \\
\text { sexualidade } \\
\text { masculina } \\
\text { na atenção à } \\
\text { saúde: gênero e } \\
\text { medicalização }\end{array}$ & $\begin{array}{c}\text { Pinheiro, } \\
\text { Couto e } \\
\text { Silva }{ }^{16}\end{array}$ & $\begin{array}{c}\text { Interface- } \\
\text { Comunicação, } \\
\text { Saúde, } \\
\text { Educação }\end{array}$ & 2001 & $\begin{array}{l}\text { Pesquisa } \\
\text { etnográfica }\end{array}$ & $\begin{array}{l}\text { Discorre sobre } \\
\text { a abordagem } \\
\text { a sexualidade } \\
\text { masculina } \\
\text { na atenção } \\
\text { primária à saúde } \\
\text { problematizando } \\
\text { as configurações } \\
\text { entre homens, } \\
\text { profissionais e } \\
\text { serviços. }\end{array}$ \\
\hline
\end{tabular}


(Continuação)

\begin{tabular}{|c|c|c|c|c|c|}
\hline Título do Artigo & Autores & Periódico & Ano & Método & Resumo \\
\hline $\begin{array}{l}\text { Novas } \\
\text { perspectivas } \\
\text { de gênero em } \\
\text { saúde }\end{array}$ & Korin $^{17}$ & $\begin{array}{c}\text { Adolescência } \\
\text { latino- } \\
\text { americana }\end{array}$ & 2001 & Ensaio & $\begin{array}{l}\text { Discorre sobre as } \\
\text { perspectivas de } \\
\text { gênero em saúde, } \\
\text { descrevendo a } \\
\text { masculinidade } \\
\text { hegemônica e suas } \\
\text { relações com a } \\
\text { saúde. }\end{array}$ \\
\hline $\begin{array}{l}\text { Por que os } \\
\text { homens } \\
\text { buscam menos } \\
\text { os serviços de } \\
\text { saúde do que } \\
\text { as mulheres? } \\
\text { As explicações } \\
\text { de homens } \\
\text { com baixa } \\
\text { escolaridade e } \\
\text { homens com } \\
\text { ensino superior }\end{array}$ & $\begin{array}{c}\text { Gomes, } \\
\text { Nascimento } \\
\text { e Araujo }{ }^{14}\end{array}$ & $\begin{array}{l}\text { Caderno de } \\
\text { Saúde Pública }\end{array}$ & 2007 & $\begin{array}{l}\text { Pesquisa } \\
\text { qualitativa }\end{array}$ & $\begin{array}{l}\text { Analisa as } \\
\text { explicações } \\
\text { presentes } \\
\text { em discursos } \\
\text { masculinos para } \\
\text { a pouca procura } \\
\text { dos homens por } \\
\text { serviços de saúde. }\end{array}$ \\
\hline $\begin{array}{l}\text { Marcas } \\
\text { identitárias } \\
\text { masculinas } \\
\text { e a saúde de } \\
\text { homens jovens }\end{array}$ & $\begin{array}{l}\text { Nascimento } \\
\text { e Gomes }{ }^{18}\end{array}$ & $\begin{array}{l}\text { Caderno de } \\
\text { Saúde Pública }\end{array}$ & 2008 & $\begin{array}{l}\text { Pesquisa } \\
\text { qualitativa }\end{array}$ & $\begin{array}{l}\text { Analisa os sentidos } \\
\text { que homens } \\
\text { jovens atribuem } \\
\text { à masculinidade, } \\
\text { discutindo acerca } \\
\text { de uma atenção } \\
\text { integral a esses } \\
\text { sujeitos no campo } \\
\text { da saúde. }\end{array}$ \\
\hline $\begin{array}{l}\text { Necessidades } \\
\text { de saúde e } \\
\text { masculinidades: } \\
\text { atenção } \\
\text { primária no } \\
\text { cuidado aos } \\
\text { homens }\end{array}$ & $\begin{array}{l}\text { Schraiber, } \\
\text { Figueiredo, } \\
\text { Gomes, } \\
\text { Couto, } \\
\text { Pinheiro, } \\
\text { Machin, } \\
\text { Silva, } \\
\text { Valença }^{10}\end{array}$ & $\begin{array}{l}\text { Cadernos de } \\
\text { Saúde Pública }\end{array}$ & 2010 & $\begin{array}{l}\text { Pesquisa } \\
\text { etnográfica }\end{array}$ & $\begin{array}{l}\text { Estudaram-se as } \\
\text { relações entre } \\
\text { masculinidade e } \\
\text { cuidado em saúde, } \\
\text { abordando o } \\
\text { reconhecimento de } \\
\text { necessidades por } \\
\text { homens usuários } \\
\text { da atenção } \\
\text { primária à saúde. }\end{array}$ \\
\hline
\end{tabular}


(Continuação)

\begin{tabular}{|c|c|c|c|c|c|}
\hline Título do Artigo & Autores & Periódico & Ano & Método & Resumo \\
\hline $\begin{array}{l}\text { O homem } \\
\text { na atenção } \\
\text { primária } \\
\text { à saúde: } \\
\text { discutindo (in) } \\
\text { visibilidade } \\
\text { a partir da } \\
\text { perspectiva de } \\
\text { gênero }\end{array}$ & $\begin{array}{l}\text { Couto, } \\
\text { Pinheiro, } \\
\text { Valença, } \\
\text { Machin, } \\
\text { Silva, } \\
\text { Gomes, } \\
\text { Schraiber, } \\
\text { Figueiredo }{ }^{19}\end{array}$ & $\begin{array}{c}\text { Interface- } \\
\text { Comunicação, } \\
\text { Saúde, } \\
\text { Educação }\end{array}$ & 2010 & $\begin{array}{l}\text { Pesquisa } \\
\text { etnográfica }\end{array}$ & $\begin{array}{l}\text { Busca compreender } \\
\text { a invisibilidade } \\
\text { dos homens no } \\
\text { cotidiano da } \\
\text { assistência a partir } \\
\text { da perspectiva de } \\
\text { gênero. }\end{array}$ \\
\hline $\begin{array}{l}\text { A influência de } \\
\text { um programa } \\
\text { de educação } \\
\text { na saúde do } \\
\text { homem }\end{array}$ & $\begin{array}{l}\text { Leite, } \\
\text { Ferreira, } \\
\text { Souza, } \\
\text { Nunes, } \\
\text { Castro }^{3}\end{array}$ & $\begin{array}{l}\text { O mundo da } \\
\text { saúde }\end{array}$ & 2010 & $\begin{array}{c}\text { Pesquisa } \\
\text { Quanti- } \\
\text { Qualitativa }\end{array}$ & $\begin{array}{l}\text { Propiciou aos } \\
\text { indivíduos do } \\
\text { sexo masculino } \\
\text { conhecimentos } \\
\text { sobre aspectos } \\
\text { gerais de saúde } \\
\text { e, em seguida, } \\
\text { verificaram-se } \\
\text { os impactos } \\
\text { alcançados. }\end{array}$ \\
\hline $\begin{array}{l}\text { Olhar } \\
\text { masculino } \\
\text { acerca do } \\
\text { atendimento } \\
\text { na estratégia } \\
\text { saúde da } \\
\text { família }\end{array}$ & $\begin{array}{c}\text { Brito, Santos } \\
\text { e Maciel }^{20}\end{array}$ & Revista Rene & 2010 & $\begin{array}{l}\text { Pesquisa } \\
\text { Qualitativa }\end{array}$ & $\begin{array}{l}\text { Identificou-se } \\
\text { a opinião de } \\
\text { homens sobre } \\
\text { o atendimento } \\
\text { recebido na } \\
\text { Estratégia Saúde da } \\
\text { Família. }\end{array}$ \\
\hline $\begin{array}{l}\text { Concepções } \\
\text { de gênero } \\
\text { de homens } \\
\text { usuários e } \\
\text { profissionais } \\
\text { de saúde } \\
\text { de atenção } \\
\text { primária e } \\
\text { os possíveis } \\
\text { impactos } \\
\text { na saúde da } \\
\text { população } \\
\text { masculina, São } \\
\text { Paulo, Brasil }\end{array}$ & $\begin{array}{l}\text { Figueiredo e } \\
\text { Schraiber }^{15}\end{array}$ & $\begin{array}{l}\text { Ciência } \\
\text { \& Saúde } \\
\text { Coletiva }\end{array}$ & 2011 & $\begin{array}{c}\text { Pesquisa } \\
\text { quantitativa }\end{array}$ & $\begin{array}{l}\text { Estudou-se a } \\
\text { relação entre } \\
\text { o exercício da } \\
\text { masculinidade } \\
\text { com o cuidado } \\
\text { em saúde para } \\
\text { homens na atenção } \\
\text { primária, por meio } \\
\text { de representações } \\
\text { e significados } \\
\text { de usuários e } \\
\text { profissionais de } \\
\text { saúde. }\end{array}$ \\
\hline $\begin{array}{l}\text { A atenção } \\
\text { básica à saúde } \\
\text { do homem } \\
\text { sob a ótica } \\
\text { do usuário: } \\
\text { um estudo } \\
\text { qualitativo de } \\
\text { três serviços do } \\
\text { Rio de Janeiro }\end{array}$ & $\begin{array}{l}\text { Gomes, } \\
\text { Rebello, } \\
\text { Nascimento, } \\
\text { Deslandes e } \\
\text { Moreira }^{21}\end{array}$ & $\begin{array}{l}\text { Ciência } \\
\text { \& Saúde } \\
\text { Coletiva }\end{array}$ & 2011 & $\begin{array}{c}\text { Pesquisa } \\
\text { quantitativa }\end{array}$ & $\begin{array}{l}\text { Analisou-se a } \\
\text { opinião do usuário } \\
\text { em relação ao } \\
\text { atendimento } \\
\text { prestado no âmbito } \\
\text { da atenção básica. }\end{array}$ \\
\hline
\end{tabular}


(Continuação)

\begin{tabular}{|c|c|c|c|c|c|}
\hline Título do Artigo & Autores & Periódico & Ano & Método & Resumo \\
\hline $\begin{array}{l}\text { Os homens } \\
\text { não vêm! } \\
\text { Ausência e/ou } \\
\text { invisibilidade } \\
\text { masculina } \\
\text { na atenção } \\
\text { primária }\end{array}$ & $\begin{array}{l}\text { Gomes, } \\
\text { Moreira, } \\
\text { Nascimento, } \\
\text { Rebello, } \\
\text { Couto, } \\
\text { Schraiber }^{22}\end{array}$ & $\begin{array}{l}\text { Ciência } \\
\text { \& Saúde } \\
\text { Coletiva }\end{array}$ & 2011 & $\begin{array}{c}\text { Pesquisa } \\
\text { quantitativa }\end{array}$ & $\begin{array}{l}\text { Discute-se a } \\
\text { ausência e/ou } \\
\text { invisibilidade } \\
\text { masculina nos } \\
\text { serviços de atenção } \\
\text { primária, com } \\
\text { consequente } \\
\text { ausência da } \\
\text { inclusão dos } \\
\text { homens nos } \\
\text { cuidados } \\
\text { preventivos. }\end{array}$ \\
\hline $\begin{array}{l}\text { O atendimento } \\
\text { à saúde de } \\
\text { homens: estudo } \\
\text { qualitativo em } \\
\text { quatro estados } \\
\text { brasileiros }\end{array}$ & $\begin{array}{c}\text { Gomes, } \\
\text { Schraiber, } \\
\text { Couto, } \\
\text { Valença, } \\
\text { Silva, } \\
\text { Figueiredo, } \\
\text { Barbosa, } \\
\text { Pinheiro }\end{array}$ & $\begin{array}{c}\text { Physis: Revista } \\
\text { de Saúde } \\
\text { Coletiva }\end{array}$ & 2011 & $\begin{array}{l}\text { Pesquisa } \\
\text { qualitativa }\end{array}$ & $\begin{array}{l}\text { Analisa os sentidos } \\
\text { atribuídos por } \\
\text { usuários do sexo } \\
\text { masculino ao } \\
\text { atendimento } \\
\text { prestado no } \\
\text { âmbito da atenção } \\
\text { primária à saúde, } \\
\text { buscando subsídios } \\
\text { para a construção } \\
\text { de indicadores de } \\
\text { satisfação. }\end{array}$ \\
\hline $\begin{array}{l}\text { Masculinidades } \\
\text { e práticas de } \\
\text { saúde na região } \\
\text { metropolitana } \\
\text { de Belo } \\
\text { Horizonte - MG }\end{array}$ & $\begin{array}{l}\text { Nascimento, } \\
\text { Trindade, } \\
\text { Gianordoli- } \\
\text { Nascimento, } \\
\text { Pereira, } \\
\text { Silva, } \\
\text { Cerello }^{24}\end{array}$ & $\begin{array}{l}\text { Saúde e } \\
\text { Sociedade }\end{array}$ & 2011 & $\begin{array}{c}\text { Pesquisa } \\
\text { Quantitativa }\end{array}$ & $\begin{array}{l}\text { Buscou identificar } \\
\text { e analisar as } \\
\text { representações } \\
\text { sociais de saúde } \\
\text { e doença e as } \\
\text { práticas de saúde } \\
\text { masculina. }\end{array}$ \\
\hline $\begin{array}{l}\text { Promoção e } \\
\text { prevenção à } \\
\text { saúde sexual } \\
\text { masculina: } \\
\text { desafios das } \\
\text { Equipes de } \\
\text { Saúde da } \\
\text { Família José } \\
\text { Pinheiro } 1\end{array}$ & $\begin{array}{l}\text { Siqueira, } \\
\text { Silva, } \\
\text { Benevides, } \\
\text { Almeida, } \\
\text { Lima, }^{25} \\
\text { Bisnet }^{25}\end{array}$ & $\begin{array}{l}\text { Revista } \\
\text { Brasileira de } \\
\text { Ciências da } \\
\text { Saúde }\end{array}$ & 2011 & $\begin{array}{c}\text { Pesquisa } \\
\text { Quanti- } \\
\text { Qualitativa }\end{array}$ & $\begin{array}{l}\text { Avaliou-se a } \\
\text { implementação das } \\
\text { ações em saúde } \\
\text { do homem, em } \\
\text { especial a sexual, } \\
\text { executada pela } \\
\text { equipe em questão. }\end{array}$ \\
\hline
\end{tabular}


(Conclusão)

\begin{tabular}{|c|c|c|c|c|c|}
\hline Título do Artigo & Autores & Periódico & Ano & Método & Resumo \\
\hline $\begin{array}{l}\text { Política de } \\
\text { saúde do } \\
\text { homem: } \\
\text { perspectivas } \\
\text { de enfermeiras } \\
\text { para sua } \\
\text { implementação }\end{array}$ & $\begin{array}{c}\text { Alvarenga, } \\
\text { Silva, Costa } \\
\text { Silva, } \\
\text { Barbosa, } \\
\text { Rocha }^{26}\end{array}$ & $\begin{array}{c}\text { Revista } \\
\text { Brasileira de } \\
\text { Enfermagem }\end{array}$ & 2012 & $\begin{array}{l}\text { Pesquisa } \\
\text { qualitativa }\end{array}$ & $\begin{array}{l}\text { Descreve e analisa } \\
\text { a percepção das } \\
\text { enfermeiras da } \\
\text { Estratégia Saúde } \\
\text { da Família acerca } \\
\text { da importância e } \\
\text { perspectivas de } \\
\text { implementação da } \\
\text { Política de Saúde } \\
\text { do Homem }\end{array}$ \\
\hline $\begin{array}{l}\text { A saúde do } \\
\text { homem na } \\
\text { visão dos } \\
\text { enfermeiros de } \\
\text { uma Unidade } \\
\text { Básica de Saúde }\end{array}$ & $\begin{array}{l}\text { Silva, } \\
\text { Furtado, } \\
\text { Guilhon, } \\
\text { Souza, } \\
\text { David }^{27}\end{array}$ & $\begin{array}{c}\text { Escola Anna } \\
\text { Nery }\end{array}$ & 2012 & $\begin{array}{l}\text { Pesquisa } \\
\text { qualitativa }\end{array}$ & $\begin{array}{l}\text { Buscou-se conhecer } \\
\text { e entender o } \\
\text { perfil masculino } \\
\text { em relação ao } \\
\text { atendimento à } \\
\text { saúde na visão } \\
\text { de enfermeiros } \\
\text { inseridos na } \\
\text { Atenção Primária à } \\
\text { Saúde. }\end{array}$ \\
\hline $\begin{array}{l}\text { Concepções } \\
\text { e práticas } \\
\text { de cuidado } \\
\text { na visão de } \\
\text { homens }\end{array}$ & $\begin{array}{l}\text { Silva, Budó, } \\
\text { Moreira da } \\
\text { Silva }^{28}\end{array}$ & $\begin{array}{c}\text { Texto } \\
\text { \&Contexto } \\
\text { Enfermagem }\end{array}$ & 2013 & $\begin{array}{l}\text { Pesquisa } \\
\text { qualitativa }\end{array}$ & $\begin{array}{l}\text { Descreve as } \\
\text { concepções e } \\
\text { as práticas de } \\
\text { cuidado a partir } \\
\text { da percepção de } \\
\text { homens residentes } \\
\text { na área de } \\
\text { abrangência de } \\
\text { uma Estratégia de } \\
\text { Saúde da Família. }\end{array}$ \\
\hline $\begin{array}{l}\text { Atendimento } \\
\text { à população } \\
\text { masculina em } \\
\text { Unidade Básica } \\
\text { Saúde da } \\
\text { Família: } \\
\text { motivos para a } \\
\text { (não) procura }\end{array}$ & $\begin{array}{l}\text { Veira, } \\
\text { Oliveira } \\
\text { Gomes, } \\
\text { Borba, } \\
\text { Costa }^{29}\end{array}$ & $\begin{array}{c}\text { Escola Anna } \\
\text { Nery }\end{array}$ & 2013 & $\begin{array}{c}\text { Pesquisa } \\
\text { Quanti- } \\
\text { Qualitativa }\end{array}$ & $\begin{array}{l}\text { Buscou conhecer } \\
\text { os motivos que } \\
\text { levam os homens } \\
\text { a procurarem } \\
\text { atendimento de } \\
\text { saúde e os motivos } \\
\text { que os afastam do } \\
\text { atendimento de } \\
\text { saúde prestado em } \\
\text { uma Unidade de } \\
\text { Saúde da Família }\end{array}$ \\
\hline
\end{tabular}

Fonte: elaborado pelos autores

Constata-se, segundo os dados analisados, que as publicações sobre o referido tema aumentaram nos últimos anos, uma vez que, de 2001 a 2008, foram quatro, concentrando a maior parte das publicações. Entre os anos de 2010 e 2013, foram 
14, o que condiz com a realidade, uma vez que, segundo Figueiredo e Schraiber, ${ }^{15}$ os estudos referentes à saúde masculina são recentes e buscam compreender as distintas motivações para os altos perfis de morbimortalidade entre os homens.

É possível observar, ainda, predominância de alguns autores nas publicações, tendo Romeu Gomes o maior número de publicações na área, estando presente como um dos autores em sete dos 18 artigos analisados. Outros pesquisadores também são notados como integrantes de grupos de pesquisa na área, destacando-se, entre eles: Lilia Schraiber, Wagner Figueiredo, Elaine Nascimento e Márcia Thereza Couto.

Em relação à metodologia utilizada, a maioria dos trabalhos utiliza o método qualitativo como ferramenta de trabalho.

Com vista à faixa etária da população estudada, verifica-se predominância de homens jovens, sendo que grande parte dos estudos analisou um grupo com média de idade de 20 a 59 anos de idade, o que condiz com a realidade, uma vez que, segundo Lauren et al. ${ }^{7}$, essa parcela da população é especialmente atingida pelas diversas causas de mortalidade e morbidade no âmbito mundial. Esse padrão é notado também no Brasil. Por outro lado, a população com idade superior a 59 anos fica desamparada, sendo as ações à saúde voltadas aos programas de saúde do idoso, sem considerar, por vezes, as peculiaridades da saúde do homem. Nessa perspectiva, os estudos revelam a existência de um espaço para pesquisa com essa faixa etária, uma vez que, com a inversão da pirâmide etária, há acentuado crescimento dessa clientela.

A partir das temáticas dos artigos e do agrupamento dessas ideias em torno de núcleos de sentidos, chegou-se a três temas que podem sintetizar a produção analisada. São eles: o imaginário masculino; as principais barreiras na busca pelo serviço; e a atuação do profissional de saúde frente às ações de saúde do homem.

\section{Imaginário masculino}

O tema referente às questões do imaginário masculino é o foco central no conjunto das fontes estudadas, estando presente na maioria das publicações de forma implícita ou explicita. Os estudos ressaltam um modelo de masculinidade hegemônica segundo a qual o homem é identificado como sendo provedor, dominador e heterossexual, associando as necessidades de saúde com demonstração de fraqueza. ${ }^{18}$

Compreende-se por masculinidade hegemônica um conjunto de elementos articulados, como crenças, atitudes e práticas, que servem de referência para a definição de ser homem em um determinado contexto. ${ }^{24}$ Ser homem é sinônimo de não ter medo, não chorar, não demonstrar sentimentos, arriscar-se diante do perigo, demonstrar coragem e ser ativo. ${ }^{30}$ 
Essas marcas culturais podem gerar agravos à saúde, pelo fato de levar o homem a assumir comportamentos pouco saudáveis, favorecendo a adoção de comportamentos de risco. ${ }^{18}$

A baixa procura por serviços de saúde evidencia a forte influência em relação ao imaginário masculino. A não adesão aos serviços de saúde pela população masculina pode ser explicada por fatores culturais. Em termos gerais, o cuidado com a saúde não é visto como uma prática masculina. ${ }^{5}$

O medo de descobrir uma doença também é abordado como uma barreira na busca pelo atendimento. Os usuários temem que, ao buscarem o serviço para a realização de ações preventivas, possa ser diagnosticada alguma doença, levando-o à necessidade de tratamento. A vergonha de se expor a um profissional também é citada como uma explicação para a não adesão aos serviços de saúde. Possivelmente, essa vergonha está associada à falta de hábito de se expor ao profissional de saúde; ao contrário da mulher, que, em seu processo de socialização, habituou-se a ter seu corpo exposto. ${ }^{14}$

Homens manifestam dificuldade na busca por assistência à saúde em razão da percepção de que o cuidado é tarefa estritamente feminina. Demandar por cuidados é algo que desmerece o seu ideal de prover. Sendo assim, essa imagem invulnerável pode prejudicar ações de autocuidado, tornando-o mais vulnerável a diversos tipos de agravos à saúde. Assim, muitas vezes, os homens negam a existência de dor ou sofrimento para reforçar um ideal de força e masculinidade em busca de uma diferenciação do feminino. ${ }^{31}$

Diferentemente das mulheres, os homens procuram o serviço quando já se manifesta a doença, valorizando mais as práticas de cura, não se reconhecendo necessidades de orientações preventivas e de promoção. A prevenção e a promoção da saúde são práticas tipicamente femininas. Esse é o principal aspecto lembrado no uso frequente dos serviços que fazem as mulheres, podendo ser compreendida como parte da concepção tradicional de gênero, em que as mulheres seriam mais frágeis e mais complicadas em sua saúde e também por ser atribuição feminina o cuidar de si própria e dos homens. ${ }^{10}$

Estudos realizados documentam tensões masculinas diante de padrõestradicionais construídos para fomentar alguns marcos vigentes de afirmação da identidade masculina: a iniciação sexual com prostitutas; a negação do homossexualismo; a referência constante a certo padrão de comportamento sexual; e o desejo de corresponder às expectativas sociais. Os homens expressam medo de serem questionados na sua masculinidade pelo fato de esse questionamento os afastar dos padrões tradicionais. ${ }^{32}$

A construção desse imaginário pode ser evidenciada pela divergência notável que existe na forma de criação entre meninos e meninas. Os meninos são instruídos desde a infância para as funções de provedores e protetores. São, também, orientados, desde cedo, a suportarem sem expressar sentimentos de dor física ou emocional, para não serem igualados ao nível da condição feminina. ${ }^{4}$ 
Atribui-se ao homem uma imagem identitária ligada ao não ser homossexual, a não ser mulher, a ser forte, capaz e protetor, violento, decidido e corajoso. Essas condutas machistas, que, por um lado, reforçam o ideal de ser homem, em contrapartida, dificultam as práticas de autocuidado. ${ }^{4}$

Nesse sentido, o imaginário masculino pode dificultar a adoção de práticas de autocuidado, pois, à medida que o homem é visto como viril, invulnerável e forte, buscar o serviço de saúde, numa perspectiva preventiva, poderia associá-lo à fragilidade, ao medo eà insegurança, consequentemente, o que implicaria provavelmente desconfianças acerca dessa masculinidade socialmente instituída. ${ }^{14}$

Diante disso, é possível perceber a influência das questões culturais nas ações de autocuidado na população masculina. A percepção de invulnerabilidade favorece a pouca demanda dos homens nos serviços. ${ }^{25}$ Manter-se invulnerável faz parte do exercício de poder entre os homens e esse poder possui um preço, o de uma vida mais curta e menos saudável, que os homens não estão dispostos a pagar. ${ }^{8}$

\section{Principais barreiras encontradas na busca pelo serviço}

Além das questões que envolvem o imaginário masculino, os estudos analisados identificam a existência de barreiras para a presença masculina nos serviços de Atenção Primária à Saúde, fatores que serão discutidos a seguir.

Para Gomes e Nascimento, ${ }^{33}$ as dificuldades relacionam-se à identidade de gênero, visto que a noção de invulnerabilidade dificultaria a verbalização de suas necessidades de saúde.

Homens inseridos em contextos sociais diversos possuem semelhante percepção sobre a saúde. Embora não neguem as necessidades de saúde, destacam várias dificuldades em procurarem os serviços e afirmam, ainda, que preferem retardar ao máximo a busca por assistência. E só o fazem quando não conseguem mais lidar sozinhos com seus sintomas. ${ }^{10-29}$

Esse perfil na busca pela assistência influencia na maneira de utilização do serviço e faz com que o homem entre no serviço de saúde pela atenção especializada, trazendo como consequências o agravo da morbidade pelo retardamento na atenção e o alto custo para o sistema de saúde. Sendo assim, é necessário fortalecer e qualificar a atenção primária, garantindo a promoção da saúde e a prevenção aos agravos evitáveis. ${ }^{6}$

Além dessas questões, cabe ressaltar outros fatores que dificultam o acesso desses indivíduos aos serviços de saúde, como indisponibilidade de tempo e horários de funcionamento das unidades incompatíveis com sua rotina de trabalho.

O trabalho assume para o homem a condição necessária para o cumprimento de seus deveres e obrigações, do papel de manter, proteger e cuidar da família - algo importante na construção da identidade masculina. ${ }^{15}$ 
Nessa perspectiva, o trabalho assume uma barreira na busca pelo serviço, uma vez que a impossibilidade de ausência no serviço profissional e a consequente falta de tempo para recorrer a um atendimento impossibilita o homem de cuidar da sua própria saúde. Outro aspecto também é válido: problemas relacionados ao desemprego podem comprometer o bem-estar de homens, pois, nessa condição, sentem-se incapacitados em cumprir com as suas obrigações. ${ }^{33}$

A ideia de provedor da família ancorada na sustentabilidade e na materialidade fornecida pelo trabalho pode fazer com que o homem negligencie sua saúde. ${ }^{20}$ Por outro lado, a existência de um vínculo de emprego pode proporcionar momentos de cuidados com a saúde, ainda que como uma forma de exigência burocrática a ser cumprida. ${ }^{14}$

Os horários de funcionamento das instituições públicas de saúde nem sempre são compatíveis com o horário de pessoas inseridas no mercado de trabalho. Dificilmente se encontram unidades de saúde abertas após as 17 horas, fato que dificulta a procura por atendimento. $^{4}$

Segundo autores ${ }^{19}$, nos serviços de saúde que expandem o funcionamento para além do horário habitual, disponibilizando atendimento em turnos de 24 horas aos sábados ou num terceiro turno à noite, tem sido possível notar a presença mais representativa de homens. A concentração de homens nesses horários demonstra considerável eficácia na estratégia de criar horários alternativos para o atendimento, especialmente dos trabalhadores.

Estudos realizados em quatro estados brasileiros revelam uma percepção dos usuários de que o serviço deveria ser rápido e pontual e, por esse motivo, dão prioridade aos hospitais e os prontos-socorros. Muitos usuários reclamam da falta de profissionais e de frequentes adiamentos das consultas ou exames ou até da ausência de um urologista, que lhes parece o profissional mais apropriado para atender essa camada populacional. Outra queixa é a da falta de medicamentos ou outros recursos, além da baixa qualidade do atendimento. ${ }^{10}$

Existe prevalência na procura por serviços de emergência, como farmácias e prontos-socorros, por responderem mais objetivamente às suas demandas. Nesses espaços, eles conseguem expor seus problemas com mais facilidade, além de o funcionamento 24 horas desses estabelecimentos facilitar aos homens a procura. ${ }^{14}$

Como indicador de rapidez e pontualidade, entende-se o tempo entre a procura por atendimento e a sua efetivação. Assim, constatou-se que essa demora está relacionada ao longo período de espera no que diz respeito à efetivação do atendimento e à resolutividade do problema. Ressalta-se, ainda, um acolhimento deficiente por parte dos profissionais. Essa ausência no acolhimento pode estar ligada ao despreparo do profissional em lidar com a população masculina. Também, a pouca resolutividade da rede leva à formação de filas que contribuem para a evasão dos usuários. ${ }^{22}$ 
Fatores ambientais também são mencionados por essa população como dificultadores no acesso aos serviços de saúde, uma vez que esses ambientes são, em sua maioria, voltados para o público feminino ou infantil. Tais fatores dificultam a presença e a permanência dos homens nesses ambientes. Estudiosos da área ${ }^{19}$ ilustram essa realidade, destacando que, na maior parte das unidades, são encontrados, em áreas comuns e de grande circulação como recepção e sala de espera, muitos materiais educativos produzidos pelo Ministério da Saúde veiculando mensagens de promoção da saúde, de temas como promoção do aleitamento materno, pré-natal, prevenção de infecções sexualmente transmissíveis (ISTs), que exibem forte conotação feminina. Além disso, há os materiais decorativos produzidos internamente que também possuem como alvo a população feminina e a infantil.

A inexistência de profissionais, programas e campanhas voltadas especificamente para a saúde do homem também constitui uma barreira para sua presença nas unidades de saúde. ${ }^{31}$

\section{A atuação do profissional na atenção à saúde do homem}

Os profissionais de saúde também são reconhecidos pelos usuários com um fator adverso na procura por atendimento. Na maioria dos casos, os profissionais utilizam condutas hospitalocêntricas, tendo como foco principal a medicalização e a cura, deixando em segundo plano as ações de promoção.

Outro aspecto notável nos serviços é que a comunicação e as práticas educativas são, em sua maioria, exercidas de forma instrucional e autoritária, indicando o que as pessoas devem ser ou fazer, dificilmente ocorrendo formas dialogadas de comunicação que contemplem o interesse dos usuários. Reproduzem-se antigos padrões da educação sanitária, com estímulo aos cuidados pela ameaça de morte e exploração dos medos, e barreiras culturais da população. ${ }^{10}$

Autores informam que os serviços de saúde destinam menos tempo dos seus profissionais aos homens e oferecem explicações breves sobre os fatores de risco para aquisição de doenças quando comparados aos destinados às mulheres. ${ }^{19}$

Esses profissionais não reconhecem a participação nessa construção cultural do adoecimento e do autocuidado. Não reconhecem que, no plano das práticas assistenciais, atuam valorizando doenças e casos graves, sobre os quais operam as mesmas reduções biomédicas. A maioria das consultas tem atendimento rápido, de pouca atenção para conversas que extrapolariam a objetividade da consulta e dão ênfase às informações voltadas estritamente para sinais e sintomas da doença. Assim, valorizam-se perguntaschave da racionalidade biomédica que Ihes permitem o caminho mais efetivo para alcançar a terapêutica. ${ }^{10}$

Embora esses profissionais reconheçam que homens possuem necessidades de atendimento, é frequente terem dificuldades para atuar sobre elas, o que é justificado 
pela forma como os homens buscam os serviços. Os profissionais relatam que eles só procuram cuidados para ações curativas. Segundo seus relatos, os homens só se admitem portadores de necessidades quando percebem alguma doença instalada ou quando sentem dor. ${ }^{10}$

É comum profissionais defenderem que os homens, além de menos presentes e assíduos, oferecem mais resistência aos convites para comparecerem ao serviço, faltam mais às consultas marcadas e não seguem o tratamento como esperado. É ainda enfatizado por eles que a participação masculina é restrita, não por responsabilidade direta dos serviços de saúde, mas por fatores do gênero, segundo os quais os homens não procuram os serviços desmotivados pela cultura machista, pela falta de tempo, pelo desvalor das questões ligadas à saúde e pela inexistência de práticas políticas que viabilizem o atendimento dessa população. ${ }^{19}$

Por outro lado, a construção desse imaginário produz no profissional uma expectativa de que os homens não cuidam de si. Nessa perspectiva, suas ações acabam por reforçar essa invisibilidade, não reconhecendo o homem como potencial sujeito nas ações de prevenção e promoção da saúde. Quando este não é reconhecido como potencial sujeito de cuidado, o profissional deixa de estimulá-lo às práticas de promoção e prevenção da saúde ou não reconhece casos em que demonstra tais comportamentos. ${ }^{19}$

Dessa forma, não se pode afirmar que a reduzida presença e a pouca vinculação com as atividades oferecidas pelo serviço por parte dos homens são de responsabilidade exclusiva dos profissionais, já que os homens, ao responderem às conformações de um padrão de masculinidade tradicional, reproduzem o imaginário social que os distancia das práticas de prevenção e promoção. ${ }^{33}$

Fica evidente a necessidade da requalificação da resposta assistencial para obtê-la de modo integral, pois a complexidade da atenção primária não é superposta à das doenças, devendo reconstruir-se como produção de cuidados até para desconstruir junto aos usuários a medicalização como a única e melhor leitura das necessidades de saúde. ${ }^{10}$

O fato de o serviço de saúde ser composto em sua maior parte por profissionais do sexo feminino dificulta a abordagem de alguns temas, principalmente os relacionados ao campo da sexualidade, em que a presença de um profissional do sexo masculino poderia ser um facilitador. ${ }^{22}$

Estudos revelam a existência de uma ideia, por parte dos profissionais, de não pertencimento dos usuários ao espaço, em razão das políticas de saúde e dos aspectos sociais. Cabe ainda ressaltar que, diante da dificuldade de acesso ao serviço, os profissionais não percebem qualquer necessidade de readequação no funcionamento do serviço, já que a mudança desse quadro ficaria a cargo do comportamento individual do usuário. ${ }^{10}$ 
Fica evidente a necessidade da readequação dos profissionais em relação tanto à percepção como ao atendimento, uma vez que não existe, durante a graduação, preparação para lidar com as demandas específicas dessa camada populacional e atendêlas. ${ }^{34}$ Essa necessidade é reiterada na própria Política Nacional de Atenção Integral à Saúde do Homem, visto que uma das suas propostas é a qualificação profissional para o atendimento aos homens.

\section{CONSIDERAÇÕES FINAIS}

Constatou-se que as publicações se concentraram mais entre os 2010 e 2013, com predominância de estudos qualitativos e com foco nos homens jovens (entre 20 a 59 anos de idade). Sobre as discussões acerca dos pontos que dificultam o acesso dos homens aos serviços de saúde, emergiram-se o modelo de masculinidade hegemônica segundo o qual o homem é identificado como sendo provedor, dominador e não vulnerável, associando as necessidades de saúde com demonstração de fraqueza. Além disso, destacaram-se as barreiras vivenciadas durante esta busca, focando na indisponibilidade de tempo e horários de funcionamento das unidades que são incompatíveis com as rotinas laborais dos homens. Por fim, os autores analisados enfatizaram a atuação do profissional na atenção à saúde do homem com condutas hospitalocêntricas, reproduzindo comunicação e práticas educativas de forma instrucional e autoritária, não considerando a singularidade dos homens, o que os afasta do serviço. Destaca-se a formação e preparo dos profissionais nesta assistência, assim como preconiza a Política Nacional de Atenção Integral à Saúde do Homem.

Além disso, é importante inferir que a produção científica acerca do tema abordado ainda é muito restrita, reforçando a necessidade de aprofundamento no assunto numa perspectiva relacional de gênero e saúde, a fim de entender melhor essa relação, podendo intervir nesse contexto de maneira mais efetiva, conhecendo as expectativas masculinas e adequando os serviços para atender às suas demandas.

Sendo assim, esta pesquisa refuta o senso comum, que considera o homem o "sexo forte", haja vista que eles se mostram mais vulneráveis em vários aspectos. Ou seja, por se sentirem invulneráveis, os homens se expõem mais aos riscos, tornando-se, de fato, vulneráveis. O "forte" não é o homem, mas sim o imaginário social que coloca o homem nesse lugar.

Deve-se levar em consideração a necessidade de mudança do enfoque em relação à priorização de ações que atendam a essa camada populacional, colocando em prática a política pública voltada para essa população e inserindo o homem no serviço de Atenção Primária à Saúde, com a promoção de uma mudança no paradigma atual.

A adoção de práticas educativas junto à comunidade poderia contribuir para a aproximação dos homens com o serviço, o que asseguraria a busca pelo serviço para 
ações de prevenção e promoção, diminuindo o absenteísmo e possibilitando mudanças no estilo de vida, com a diminuição das taxas de mortalidade nesse grupo populacional.

\section{REFERÊNCIAS}

1. Brasil. Ministério da Saúde. Portaria $N^{\circ} 2.488$, de 21 de outubro de 2011. Aprova a Política de Atenção Básica, estabelecendo a revisa de diretrizes e normas para a organização da Atenção Básica, para Estratégia Saúde da Família (ESF) e o Programa de Agentes Comunitários de Saúde (PACS). Brasília: Ministério da Saúde; 2011.

2. Albuquerque PC, Stotz EN. Popular education in primary care: in search of comprehensive health care. Interface Comunic Saúde Educ. 2004; 8(15):259-74.

3. Leite DF, Ferreira IMG, Souza MS, Nunes VS, Castro PR. A influência de um programa de educação na saúde do homem. Mundo Saúde. 2010; 1(1):50-6.

4. Braz M. The construction of the masculine subjectivity and its impact on man's health: bioethics reflection on distributive justice. Ciênc Saúde Coletiva. 2005; 10(1):97-104.

5. Schraiber LB, Gomes R, Couto MT. Homens e saúde na pauta da Saúde Coletiva. Ciênc Saúde Coletiva. 2005; 10(1):7-17.

6. Brasil. Ministério da Saúde. Portaria N 1.944, de 27 de agosto de 2009. Institui no âmbito do Sistema Único de Saúde (SUS), a Política Nacional de Atenção Integral à Saúde do Homem. Brasília: Ministério da Saúde; 2009.

7. Laurenti R, Jorge MHPM, Gotlieb SLD. Perfil epidemiológico da morbi-mortalidade masculina. Ciênc Saúde Coletiva. 2005; 10(1):35-46.

8. Carrara S, Russo JÁ, Faro L. A política de atenção à saúde do homem no Brasil: os paradoxos da medicalização do corpo masculino. Physis. 2009; 19(3):659-78.

9. Ceccarelli PR. A nova ordem repressiva. Psicol Ciênc Prof. 2010; 30(4):738-51.

10. Schraiber LB, Figueiredo WS, Gomes R, Couto MT, Pinheiro TF, Machin R.

Necessidades de saúde e masculinidades: atenção primária no cuidado aos homens. Cad Saúde Pública. 2010; 26(5): 961-70.

11. Souza MT, Silva MD, Carvalho R. Revisão integrativa: o que é e como fazer. Einstein. 2010; 8(1):102-6.

12. Mendes KDS, Silveira RCCP, Galvão CM. Integrative literature review: a research method to incorporate evidence in health care and nursing. Texto Contexto Enferm. 2008; 17(4):758-64.

13. Sousa R, Espírito Santo F. Nursing history for hospitalized oncohematologic customers: an integrative review of the literature. Rev Enferm UFPE [Internet]. 2012 
[citado em 2013 dez 15]; 7(2):608-18. Disponível em: file://C:/Users/REME\%202/ Downloads/3532-37292-1-PB.pdf.

14. Gomes R, Nascimento EF, Araújo FC. Por que os homens buscam menos os serviços de saúde do que as mulheres? As explicações de homens com baixa escolaridade e homens com ensino superior. Cad Saúde Pública. 2007; 23(30):565-74.

15. Figueiredo WS, Schraiber LB. Concepções de gênero de homens usuários e profissionais de saúde de serviços de atenção primária e os possíveis impactos na saúde da população masculina, São Paulo, Brasil. Ciênc Saúde Coletiva. 2011; 16(1):935-44.

16. Pinheiro TF, Couto MT, Silva GSN. Questões de sexualidade masculina na atenção primária à saúde: gênero e medicalização. Interface Comunic Saúde Educ. 2011; 15(38):845-58.

17. Korin D. Novas perspectivas de gênero em saúde. Adolesc Latinoam. 2001; 2(2):67-79.

18. Nascimento EF, Gomes R. Marcas identitárias masculinas e a saúde de homens jovens. Cad Saúde Pública. 2008; 24(7):1556-64.

19. Couto MT, Pinheiro TF, Valença O, Machin R, Silva GSN, Gomes R, et al. O homem na atenção primária à saúde: discutindo (in)visibilidade a partir da perspectiva de gênero. Interface Comunic Saúde Educ. 2010; 14(33):257-70.

20. Brito RS, Santos DA, Maciel PO. Olhar masculino acerca do atendimento na estratégia saúde da família. Rev RENE. 2010; 11(4):135-42.

21. Gomes R, Rebello LEFS, Nascimento EFN, Deslandes SF, Moreira MCN. A atenção básica à saúde do homem sob a ótica do usuário: um estudo qualitativo em três serviços do Rio de Janeiro. Ciênc Saúde Coletiva. 2011; 16(11):4513-21.

22. Gomes R, Moreira MCN, Nascimento EF, Rebello LEFS, Couto MT, Schraiber LB. Os homens não vêm! Ausência e/ou invisibilidade masculina na atenção primária. Ciênc Saúde Coletiva. 2011; 16(supl. 1):983-92.

23. Gomes R, Schraiber LB, Couto MT, Valença OAA, Silva GSN, Figueiredo WS et al. O atendimento à saúde de homens: estudo qualitativo em quatro estados Brasileiros. Physis. 2011; 21(1):113-28.

24. Nascimento ARA, Trindade ZA, Gianordoli-Nascimento IF, Pereira FB, Silva SATC, Cerello AC. Masculinidades e práticas de saúde na região metropolitana de Belo Horizonte - MG. Saúde Soc. 2011; 20(1):182-94.

25. Siqueira FAA, Silva SO, Benevides PM, Almeida MSB, Lima TNB, Prest Bisneto F. Promoção e prevenção à saúde masculina: desafios das equipes de saúde da família José Pinheiro 1. Rev Bras Ciênc Saúde. 2011; 15(2):191-200.

26. Silva PAS, Furtado MS, Guilhon AB, Souza NVDO, David HMSL. A saúde do homem na visão dos enfermeiros de uma unidade básica de saúde. Esc Anna Nery Rev Enferm. 2012; 16(3):561-8. 
27. Silva SO, Budó MLD, Silva MM. Concepções e práticas de cuidado na visão de homens. Texto Contexto Enferm. 2013; 22(2):389-96.

28. Vieira KLD, Gomes VLO, Borba MR, Costa CFS. Atendimento da população masculina em unidade básica saúde da família: motivos para a (não) procura. Esc Anna Nery Rev Enferm. 2013; 17(1):120-7.

29. Souza ER. Masculinidade e violência no Brasil: contribuições para a reflexão no campo da saúde. Ciênc Saúde Coletiva. 2005; 10(1):59-70.

30. Machin R, Couto MT, Silva GSN, Schraiber LB, Gomes R, Figueiredo WS, et al. Concepções de gênero, masculinidade e cuidados em saúde: estudo com profissionais de saúde da atenção primária. Ciênc Saúde Coletiva. 2011; 16(11):4503-12.

31. Gomes R. Sexualidade masculina e saúde do homem: proposta para uma discussão. Ciênc Saúde coletiva. 2003; 8(3):825-9.

32. Gomes R, Nascimento EF. A produção do conhecimento da saúde pública sobre a relação homem-saúde: uma revisão bibliográfica. Cad Saúde Pública. 2006; 22(5):901-11.

33. Bertolozzi MR, Nichiata LYI, Takahashi RF, Ciosak SI, Hino P, Val LF, et al. Os conceitos de vulnerabilidade e adesão na Saúde Coletiva. Rev Esc Enferm USP. 2009; 43(spec2): 1326-1330.

34. Souza e Souza LP, Almeida ER, Queiroz MA, Silva JR, Souza AAM, Figueiredo MFS. Conhecimento de uma equipe da estratégia saúde da família sobre a política de atenção à saúde masculina. Trab educ saúde. 2014; 12(2):291-304.

Submissão: junho de 2016.

Aprovação: junho de 2017. 